$\xi=-1$

\title{
Constructive basis for the development of the extreme zones of Siberia and the Russian arctic
}

\author{
Tat'yana Sarvut * \\ Institute of Construction and Architecture fsbei He National Research University \\ "Moscow State University of Civil Engineering" Moscow \\ *Corresponding author E-mail: Tatyana.123Sarvut@gmail.com
}

\begin{abstract}
The paper describes the constructive basis for building and structure designing in the difficult regions of Siberia and the Russian Arctic and development of a new approach to the design of buildings and structures in the Russian Arctic in the face of climate change. Severe climate and weather conditions of the northwestern territories of Russia are rapidly changing due to the global warming. The structural changes in development and construction, following this irreversible process, are highlighted and discussed in relation to the foundations and constructive systems. The paper provides an overview of methods and technological approaches to the extreme zone construction. The application of modern methods of design and construction with the involvement of competent "practitioners" increases the pace of construction and reduces its cost; Architectural and constructive solutions should focus on the developing areas of business and tourism. We suggest the possible protective measures against the transgression of the World Ocean and thawing of the permafrost. The term "special Arctic bases", denoting the new type of settlements in the Russian Arctic, is introduced. The introduction of constructive solutions and the development of planning solutions for the bases will help to ensure a stable activity in the region.
\end{abstract}

Keywords: Global Warming; Permafrost; Caisson Foundations; Transportation; Water Aggression.

\section{Introduction}

Current study aims to develop a new approach to the design of buildings and structures in the Russian Arctic, whose necessity is apparent under the conditions of dramatic climate changes [1-3]. We discuss the hypothesis of the ground weakening due to the permafrost thawing and the shift in the architectural and constructional paradigm.

Another phase of the industrial age is marked by the increasing interest to the extreme zones and their undeveloped resources. On the sites, where no industrial operations or dwelling have been possible, one can now create sufficient conditions for human life and activities, as well as for preservation of the natural ecosystems. Technological innovations allow to provide both physical and informational connection between the hardly accessible territories and "the Mainland".

«Russia's power will grow with Siberia and the Northern Ocean», - today these words by the great Russian scientist M. V. Lomonosov can be accepted as the program for development of the extreme zones of Siberia and the Russian Arctic [4], [5].

Addressing the problem of developing extreme zones of Siberia and the Russian Arctic is an attempt to offer a modern solution in the design of buildings and structures that can not only accelerate the pace of building the necessary infrastructure, but also preserve a unique nature. The ecological approach to architecture in Russia is replacing the traditional irrational attitude to architecture in the USSR. The development of the Siberian and Arctic regions will go in many directions: the expansion of transport infrastructure, the development of various types of tourism. The diversity of natural and cultural resources determines the trend of growing interest in tourism in the Arctic and in the North of Russia. [6],
[7]. Visitors will be attracted by glacial landscapes, snowfields and waterfalls, pristine ecosystems, unique animals in an untouched natural habitat Arctic tourism - ecological, expedition and cruise - will require the creation of a wide infrastructure.

Any human activity in the given extreme regions can and should be provided with comfortable and secure conditions. Natural and man-induced factors influence the development of the comprehensive and effective reclamation of the extreme regions of Siberia and the Russian Arctic.

\section{Materials and methods}

The study conducted a systematic analysis of the territory of the Arctic region, which is correlated with the prospects of climate change and construction methods.

Behind the development of the underdeveloped regions of Russia there is a range of aspects, corresponding to the aim of profit maximization:

- The natural resources have not been developed yet due to the harsh climate conditions, complex relief, inaccessibility and vastness of these territories, which is inseparably associated with low availability of the roadway and railroad networks;

- The strategic goals include increase in the population density (today it is equal to 1 person $/ \mathrm{km}^{2}$ in the Far North and the territories equated to its conditions), development of subsurface resources, guarding of the extensive state borders, military aspects, concerning the rising international tension;

- The existing and accumulated experience in the development of the "difficult" territories; 
- The special aspects of the design of buildings and structures require certain engineering solutions in relation to the dynamic complex "Place-conditions-object".

"Place" - the ground of the territories of interest is very diverse, and it will undergo substantial transformation under the "conditions" of changing temperature and humidity regimes in the areas of construction and exploitation of the "object" - the building/structure, exhibiting the characteristics of rapid installation, unit-based structure, and mobility.

There is a serious obstacle for the implementation of the program of the territory development, lying literally "under the surface": permafrost comprises $65 \%$ of the area of Russia

Russia is located at the subpolar latitudes, and the climate changes lead to substantial transformation of both temperature and humidity regimes, as well as of circulation. The warming has the most pronounced effects at the polar latitudes, where the temperature difference between the equator and the pole decreases, the wind velocity and the efficiency of the moist transfer to the continent are altered. Consequently, we face the declining isolation of the arctic and the southern latitudes and the increasing probability of the arctic and the southern air outbreaks. These processes will eventually lead to changes in the relief of the surface, located close to the sea level, which is transgressing at a rate of $3 \mathrm{~mm}$ per year; particularly in Russia, it will primarily affect the West Siberian Plain. The chances of local flooding in the vast territories set the following goals:

- $\quad$ to secure the transport connection between the regions;

- to elevate or transfer the settlements and the industrial facilities to a safe altitude above the sea level;

- To change the whole construction paradigm.

\section{Results}

Sufficiently high territories of the East European Plain and the Central Siberian Plateau will not undergo any radical reorganization of the infrastructure, with the exception of the estuaries of the rivers flowing into the Arctic Ocean and the settlements along the shoreline.

The complex of the listed factors - the ocean transgression and the climate warming - has serious consequences: according to the estimates of A. V. Pavlov and G. F. Gravis, the areas of permafrost degradation in Siberia will expand to $800-1500 \mathrm{~km}$ from the shoreline and will undergo waterlogging and flooding. Strengthening the foundation structures and deeper embedding will not solve the problem [8].

Today, the traditional foundation, stilt-based and detached from the ground, is still relevant. Time, however, waits for no man, and novel solutions are required.

We will have to widen the gap between the ground and the foundation and to construct the buildings at a significant height. This concept reminds the structure of a bridge; therefore, it will be rational to implement the appropriate foundations. Construction of the objects will be performed under the conditions of substantial water in flow; it will be complicated by drainage and presence of large hard rock inclusions within the ground. Thus, implementation of the caisson method for the construction of deep foundations appears to be relevant. Loose bed requires buoyant caisson foundations (the Krasnokholmsky Bridge in Moscow, $34 \mathrm{~m}$ deep), both traditional box caissons and less common shell caissons. The design by Mazur M. V. - self-locking steel and concrete piers - is relatively unknown, yet it has already been implemented. Use of turbo drilling for their installation will allow to perform the construction all year round, to decrease the drilling depth, while the pier structure provides physical and technical means for resisting the frost heaving forces in case of seasonally thawed ground. In the pile foundations, one can include dampers under the grillage for a similar purpose. Uneven subsidence of a building or a structure due to the inter seasonal temperature oscillations should be addressed through dividing it into individual settling modules.
Global climate change does not only rule out the possibility of extremely cold winters, but, on the contrary, makes them quite likely, as in winter, it manifests itself in the winter blocking anticyclones over the continents, i.e., in extremely low temperatures, whereas in summer, in droughts. These processes exacerbate the ground weakening due to the permafrost thawing, when the operating conditions of the structures, primarily of the foundations, is marked by a wide range of temperatures during the winter and the summer months. The polymer concrete, whose compressive strength is increased up to $80-120 \mathrm{MPa}$, and the freeze-thaw durability is also high, can become an irreplaceable material. Polymer concretes are virtually impervious to water. Surface-mounted and subsurface parts of the buildings/structures are designed to have reduced weight, featuring non-mineral construction materials. Polystyrene-based building materials (permanent forms), sippanels, CLT-panels will be suitable, whereas for heat insulation, polystyrene foam can be used.

Durability and stability of the buildings/structures can be provided by the module spatial design. Elevating the objects of different purpose, including the highways and the railway lines, to a high level above the ground will allow the regular traffic circulation. Apparently, the infrastructure of the industrial facilities, settlements and cities will also be based on the platforms. The design of the most susceptible elements, exposed to intense wind and downfall impact, should include shells (domes, spherical vaults etc.).

Along with the security in the continent, the issues of protecting the coastal area and the islands from the possible natural hazards should also be addressed. The regular reports on the climate changes both state and adjust the dynamics: the non-linear increase in the sea level over 50 years may equal several meters . Coastal landscape response is considered to be either static (flooding) or dynamic (active alteration of the landscape). Storms and floods, combined with the general rise in the World Ocean level, can cause inundation of the coastal territories with significant intrusion of the water into the continent. By the example of the Netherlands, the dike construction will protect individual constrained sites of land against the water aggression. In the places with non-critical levels of water rise, it would be reasonable to surround the existing settlements with dikes, adjusting the design plan to be more compact. Therefore, during certain adverse periods, the settlement confined within the dikes can be located below the sea level and still be safe. In this case, the dikes are used for the initially intended purpose - to constrain the rush of water rather than to construct the transportation networks. At the same time, it would be reasonable to promote the concept of the line road construction as the major approach to construct the main traffic arteries. Thus, the motorway and the railroad are located within the same multileveled structure, but the automobile passenger, freight and railroad traffic flows are separated. Moreover, such system would allow rapid transfer of the containers from the automobiles to the rail transporters, which would substantially decrease the need for freight motor transport on the long distance. The existing system of the territorial development with the help of railroads, traditional in Russia, is optimal. The system of communication lines under the upcoming extreme conditions should be formed on this basis, combining and amplifying it with the necessary routes. In this way, on could offset the lack of motorways between the central part of Russia and the Far East. The traffic arteries, constructed at a significant height, will allow for uninterrupted connection between the remote regions and "the Mailand". Application of the rotation working system during the first stages of the regional development is, undoubtedly, psychologically and economically reasonable. Design of the industrial facilities does not include the residential buildings for permanent accommodation. However, the existing cities can and should accumulate the workforce in the light of developing resource industries. It is, although, apparent that the promising multistage high-technology industries cannot be created on the rotation-work basis. Special Arctic bases (SAB) - a new type of settlements - should be formed as the facilities for long-term accommodation and certain type of operations (resource extraction, scientific, military, tourist 
etc.). SAB is a settlement for $15-150$ people, comprising all the necessary objects for proper autonomous functioning. We suggest construction of individual comfortable modules that can be combined into various structures [8-10]. The modules should replace the conventional accommodation units. Novel permanent residential structures will inevitable emerge at the sites of long-term development/maintenance of the objects of different purpose. Therefore, the methods for creating their own microclimate can be applied to them. First of all, it involves the general concept of the "settlement under shelter" beyond the Polar Circle. It would be reasonable to design a confined space, containing all the necessary modules - residential, public, energetic, maintenance etc. - under the common roof/vault. Low-pitched shelters of the large-span shells will provide the reliable protection from snow, wind and rain. Surely, the settlement should be standing on a platform, detached from the ground to avoid thawing. It will be possible to plant certain shrub and tree species under the dome/vault, between the buildings, on the artificial soil, and to shape peculiar microclimate. The cover can be developed on the basis of modern hightech fabrics. The design of smart fabric, containing a hybrid highpower textile capacitator, allows to accumulate and conduct energy. The operational principle of the "fabric-based electrical generator" is the combination of movement (mechanical agitation by the wind force) and sunlight. The main objective is to create a translucent structure from these materials.

One of the possible ways of implementation is construction of large-span domed/vault structures, acting as pneumoshells, i.e., requiring small excessive pressure within the dome space.

Cost-intensive methods of development of the extreme zones require proper power supply. This issue can be solved with the help of petrothermal power engineering. Today, when the oil-and-gas wells are up to $5 \mathrm{~km}$ deep, drilling down to $4 \mathrm{~km}$ is enough to reach the dry rocks that will provide the settlements with deep heat. This technology suggests inflow of cold water into one of the drilled wells and subsequent outflow of hot water (or steam) at the temperature of $350^{\circ} \mathrm{C}$. Such temperatures allow sufficiently high operating efficiency of a common thermal station, and, importantly, there is no need for devising novel equipment.

The study shows the need to change the architectural and constructive paradigm in Russian design and construction: Russia's vast expanses continue to negatively affect the development of the infrastructure of Siberia and the Arctic zone of the Russian Federation, the remoteness of designers from the construction site and, as a result, ignorance of the improvements of regional builders And their methods prove their effectiveness: - a metal road bridge with a length of $28.5 \mathrm{~m}$ is built on 4 self-fastening piles for 1 month (cost is 2.5 times lower compared to similar ones); - Hanging chain, unconscionable bridge $124.2 \mathrm{~m}$ long on 8 thermosweeps was designed and built in 2 months.

The analysis of current state and development of the construction technologies allows to formulate certain design principles for buildings and structures in the Russian Arctic:

- the necessity of wider implementation of the shell caissons and self-locking steel and concrete piers, featuring polymer concretes;

- The need for an even distribution of project teams directly across the territory of the regions.

- Analysis of 28 rotational complexes showed: 12 - large complexes of fuel and energy companies and objects of the Ministry of Defense with the number of more than 150 people belong to the expedition-shift method of organization of production, 16 - small objects of scientific and research organizations with the number of 15-30 people with expeditionary Nature of the work. Only large complexes were designed as individual objects and taking into account the necessary medical-geographical aspects. Small objects do not find investors and require reconstruction. Meanwhile, the development of a variety of types of tourism will require investments in the design and construction of similar facilities. The architectural image for them is of paramount importance.
This gives rise to the necessity of designing the architectural, planning and construction concepts of the special Arctic bases of two types: open and enclosed (based on the shells involving the use of smart fabrics).

\section{Discussion}

Public attention is continuously drawn to the natural, cultural and historical problems of the Arctic, within the framework of the Federal Arctic Forum "Arctic Days", held by the Ministry of Natural Resources and Environment of the Russian Federation with support from the Russian Academy of Sciences and Lomonosov Moscow State University. The international scientific conferences of the Forum, that has been held in November 2016 in Moscow with the participation of the Nobel Peace Laureate in 2007 - Terry Callaghan - involve a broad spectrum of the issues concerning the Arctic research. Design and construction of the objects for the purposes of all kinds of operations lay the foundation for the implementation of the state program "Social and economical development of the Arctic zone of the Russian Federation for the period through to 2020".

Expanding the possibilities of interaction between different countries Dean of Nord University Business School Erlend Bullvag devoted his report at the conference in April 2017 in Bodo, Norway. He stressed how the problem of the inadequacy of infrastructure and labor for the production of the product is particularly acute. People can live in a harsh Arctic region only if they create a comfortable and safe environment. At the same time, the Arctic region has many unsolved problems, their volume and severity can be compared with the problems of presence in Antarctica.

Current study aimed to generalize the modern experience in construction, to implement the world latest technological innovations, and to set the scope of research and impact of the climate change consequences in the Russian Arctic.

\section{Conclusion}

Ratification of the Paris Agreement on the climate changes opens wide prospects of interactions between nations, and we should take specific steps to provide the citizens of Russia and all states of the Arctic region with safe and comfortable living conditions. The design (foundations, covers, transportation), architectural and planning solutions (special Arctic bases) of the structures for the Russian Arctic can ultimately be implemented in the Arctic regions of other countries.

New approaches to the design of buildings and structures are proposed, covering a wide range of issues of development of the Siberian and Arctic regions of Russia, caused by the need to respond to climatic, demographic and resource challenges. 


\section{References}

[1] Ewing, M., Donn, W. (1956). Theory of Ice Ages, Science, 123(3207), 1061-1066.

[2] Boyarintsev, V.I. (2011). The great M. V. Lomonosov: the beginning of the Russian science. Moscow: Pskov Renaissance.

[3] Lukin, Y.F. (2016). Arctic tourism: the rating of regions, the opportunities and threats, Arctic and The Nord, 23. doi: 10.1007/s13280011-0220-y.

[4] Ershov, R.V. (2015). National Park "Russian Arctic", Arctic Bulletin, 3, 116-123.

[5] Shats, M.M. (2010). The stumbling block of permafrost, or time to save the permafrost, Territory and Planning, 3. Retrieved from: http://terraplan.ru/arhiv/50-3-27-2010/870-582.html.

[6] Pavlov, A.V. (2000). Permafrost and modern climate, Priroda, 4: 2000, 9-18.

[7] Mazur V.N. (2016). Effective foundations for the permafrost conditions. Retrieved from: http://www.mazur-most.ru/stati/effektivnyiefundamentyi-dlya-vechnoj-merzlotyi.html

[8] Sharakshane S. (2015). Global warming and global cooling. Scientific Russia, $3 . \quad$ Retrieved from: http://scientificrussia.ru/articles/globaljnoe-poholodanie.

[9] Osnovin, V.N., Shulyakov, L.V., Dubyago, D.S. (2006). Handbook on the construction materials and products, Rostov-on-Don: Phoenix Publishing.

[10] Olsen M.S., Callaghan T.V., Reist J.D., Reiersen L.O. et al. (2016) The changing arctic cryosphere and likely consequences: an overview. In Callaghan T.V., Johansson M., Prowse T.D. (Eds). The Changing Arctic Cryosphere and likely Consequences. Ambio, 40, doi: 10.1007/s13280-011-0220-y. 